\title{
Drug Release Mechanism of Slightly Soluble Drug from Nanocomposite Matrix Formulated with Zeolitel Hydrotalcite as Drug Carrier
}

\author{
Ahmad Ainurofiq ${ }^{1 *}$ and Syaiful Choiri ${ }^{1,2}$ \\ ${ }^{1}$ Department of Pharmacy, Sebelas Maret University, Ir.Sutami No. 36A, Surakarta, 57126, Indonesia, ${ }^{2}$ School of Pharmacy, \\ Institut Teknologi Bandung, Ganesha 10, Bandung, 40132, Indonesia \\ *For correspondence: Email: rofig@mipa.uns.ac.id; Tel: +6271663375, +628156672276; Fax: +6271663375
}

\begin{abstract}
Purpose: To evaluate the mechanism of drug release of a slightly soluble drug (theophylline) from nanocomposite of zeolite (ZLT) or hydrotalcite (HTC) used as drug carrier.

Methods: Nanocomposite was prepared with dispersion of either ZLT or HTC as drug carrier and theophylline (THP) as drug in drug to clay ratios of 1:2, 3:4 and 1:1. The formulations were characterized for drug release and loading. Dependent and independent kinetic models were employed to analyze the drug release data. Fourier transform infrared spectroscopy (FTIR) was used for the structural characterization of the formulations.

Results: Nanocomposite was formed due to incorporation of the drug in the basal spacing of ZLT/HTC. The drug loading of THP/ZLT and THP/HTC composites were $38.10 \%$ for $2 h$ and $27.35 \%$ for $3 h$, respectively. HTC and ZLT nanocomposite retarded drug release for $6 \mathrm{~h}$. Non-linear and Peppas-Sahlin were the best fitting kinetic release models based on the goodness of fit.

Conclusion: ZLT provides better drug loading capacity than HTC. However, both ZLT and HTC are suitable for the formulation of controlled release products. The drug release kinetics and mechanism were a combination of Fickian and non-Fickian diffusion.
\end{abstract}

Keywords: Zeolite, Hydrotalcite, Clays, Nanocomposite, Theophylline, Drug release kinetics, Basal spacing

Tropical Journal of Pharmaceutical Research is indexed by Science Citation Index (SciSearch), Scopus, International Pharmaceutical Abstract, Chemical Abstracts, Embase, Index Copernicus, EBSCO, African Index Medicus, JournalSeek, Journal Citation Reports/Science Edition, Directory of Open Access Journals (DOAJ), African Journal Online, Bioline International, Open-J-Gate and Pharmacy Abstracts

\section{INTRODUCTION}

Controlled drug delivery systems using clays, such as mesoporous silica, have been reported extensively by several researchers [1-3]. Zeolite (ZLT) and hydrotalcite (HTC) are composed of layers of large and insoluble cations, those are weakly bound to the space between interlayers [4]. Some properties of the clays include swellability, cation/anion exchange and intercalation. These properties make them promising candidate in development of drug- nanoclay composites for controlled release drug delivery systems [5,6]. ZLT and HTC have large pores and drug as guest molecules can be loaded into the nanoporous structure [7]. The nanopores are knew as basal spacing which nanocomposite can be formed naturally [8].

ZLT has smaller pores than mesoporous material that its characteristic can be used to achieve controlled release effectively. The drug as guest molecules can be loaded into pores depending on the size of the mesopores. Adsorption and 
release of molecules from this matrix are governed by size selectivity and a pore size of the order of the drug dimension provides a better control of drug release [9]. Nano composite has been successfully produced between drug and ZLT combined with biodegradable polymers (i.e. chitosan, gelatin and alginate) and prolonged the drug releases [10]. Diclofenac sodium has been loaded into natural ZLT and the drug released for $8 \mathrm{~h} \mathrm{[11].}$

HTC (anionic clay) is a two-dimensional layered double hydroxides material. This material is natural HTC with the brucite structure, where for each set of eight magnesium cations, substituted by two aluminum cations. The positive charge in excess is balanced by carbonate anions hosted together with water molecules in the interlayer [12]. The intercalation of this anionic clay and its high affinity for carbonate ion in acid medium makes it able to load the drug in the interlayers. HTC has been developed as a drug carrier using ketoprofen, sodium diclofenac and chloramphenicol succinate drug release up to 24 h $[13,14]$. HTC was used as controlled release formulation using poorly water-soluble drug and released the drug in a controlled release manner in intestinal environment [15].

The purpose of the present study was to evaluate the drug release models of nanoclaysbased matrix drug carriers of slightly watersoluble drug using ZLT and HTC to formulate controlled release tablet dosage form.

\section{EXPERIMENTAL}

\section{Materials}

Theophylline (THP; Shandong Pharm, China), lactose (DFE Pharma, The Netherlands), magnesium stearate (Peter Greven, Germany) were purchased from local suppliers, natural ZLT was obtained from Gunung Kidul (Yogyakarta, Indonesia), HTC was obtained from Sigma Aldrich (Singapore) and used as received, hydrochloric acid, dibasic potassium phosphate and sodium hydroxide were purchased form Merck (Darmstadt, Germany) and demineralized water. All the following chemicals were of analytical grade.

\section{Preparation of ZLT}

ZLT was washed with demineralized water and colloid phase was precipitated overnight. The precipitation was washed 3 times, then filtered with a vacuum filter and dried in oven at $110^{\circ} \mathrm{C}$ for $6 \mathrm{~h}$. Activation was done to open the pores of
ZLT using $500 \mathrm{~mL}$ of $\mathrm{HCl}$ (1 mol/L) was refluxed for $5 \mathrm{~h}$ at $90{ }^{\circ} \mathrm{C}$ and then washed with demineralized water until the $\mathrm{pH}$ became neutral. The ZLT was washed with $0.75 \mathrm{~mol} / \mathrm{L} \mathrm{NaOH} 500$ $\mathrm{mL}$ to build proportion of silica and aluminum and then with demineralized water until $\mathrm{pH}$ became neutral. Furthermore, it was precipitated overnight and filtered with a vacuum filter and the residue was dried in oven at a temperature of $110{ }^{\circ} \mathrm{C}$ for $6 \mathrm{~h}$. The dried ZLT was passed through 180 mesh sieve $(80 \mu \mathrm{m})$.

\section{Composites of THP/ZLT and THP/HTC}

The composite between THP and clays were prepared by dispersing $5 \%(w / v)$ ZLT or HTC in $50 \mathrm{~mL}$ aqueous medium containing of $250 \mathrm{mg}$ THP. The mixtures were stirred at $600 \mathrm{rpm}$ for 4 $\mathrm{h}$ at ambient temperature to achieve equilibrium composite between drug and ZLT/HTC. Two $\mathrm{mL}$ samples were withdrawn every $30 \mathrm{~min}$ and centrifuged at $6000 \mathrm{rpm}$ for $2 \mathrm{~min}$ using Thermo Scientific Heraeus centrifuge. The supernatant was analyzed using Hitachi U-2900 Spectrophotometer at wavelength $271.5 \mathrm{~nm}$. The sediment from centrifugation was dried in oven at $60{ }^{\circ} \mathrm{C}$ for $6 \mathrm{~h}$ and stored in desiccator until further analysis. Drug loading (DL) was computed as in Eq 1.

$D L(\%)=\left\{\left(W_{1}-W_{2}\right) / W_{1}\right\} 100$

where $W_{1}$ is the initial concentration of drug and $W_{2}$ the concentration of drug after composite formulation.

\section{FTIR spectroscopy studies}

The nanocomposite was characterized using FTIR Shimadzu 8400S (Kyoto, Japan) to determine the composite between THP and clays. THP, ZLT, HTC, THP/ZLT and THP/HTC were scanned using potassium bromide pellets in the range of wavenumber $4000-400 \mathrm{~cm}^{-1}$ with resolution $4 \mathrm{~cm}^{-1}$ and 10 times iteration. The pellets were prepared using $150 \mathrm{mg}$ potassium bromide and $1.5 \mathrm{mg}$ of samples were mixed homogenously and pressed by a hydraulic pressure at $60 \mathrm{kN}$ for $5 \mathrm{~min}$.

\section{Preparation of THP tablets}

The tablet formulations are presented in Table 1. Magnesium stearate (1\% of the tablet weight) and lactose were used as lubricant and filler, respectively. All the ingredients except the lubricant were mixed homogenously using mixer (25 rpm) for $16 \mathrm{~min}$. Demineralized water were added until a wet mass of granules was achieved. The wet granules mass were passed 
through 16 mesh sieve $(1.18 \mathrm{~mm})$ and dried in an oven at $50{ }^{\circ} \mathrm{C}$ for $3 \mathrm{~h}$. The dried granules were passed through 18 mesh sieve $(1.00 \mathrm{~mm})$. The granules were evaluated for particle size distribution using Retsch AR200 basic analytical sieving, moisture content was done using Ohaus EB-340 moisture analyzer balance. The dried granules and magnesium stearate were mixed using mixer (25 rpm) for $4 \mathrm{~min}$. Further characterization of granules was conducted to determine flow time, angle of repose and compactibility with deepness of upper and lower punch at 5.30 and $8.15 \mathrm{~mm}$, respectively.

The granules were compressed into tablets. The weight of tablet was adjusted $500 \mathrm{mg}$ and the hardness was kept at $100-120 \mathrm{~N}$ and tested by Gouming YD-01 hardness tester.

Table 1: Composition of the formulated tablets

\begin{tabular}{lccc}
\hline \multirow{2}{*}{ Batch } & \multicolumn{3}{c}{ Composition (\% w/w) } \\
\cline { 2 - 4 } & Theophylline & Zeolite & Hydrotalcite \\
\hline F1 & 40 & - & - \\
F2 & 40 & 20 & - \\
F3 & 40 & 30 & - \\
F4 & 40 & 40 & - \\
F5 & 40 & - & 20 \\
F6 & 40 & - & 30 \\
F7 & 40 & - & 40 \\
\hline
\end{tabular}

\section{Drug release study}

Drug release testing was performed using Electrolab TDT-08L dissolution tester model USP apparatus type II with $75 \mathrm{rpm}$ speed rotation and temperature was maintained at $37 \pm 0.5{ }^{\circ} \mathrm{C}$. A $900 \mathrm{~mL}$ phosphate buffer $\mathrm{pH} 4.5$ was used as dissolution medium. Ten milliliters of aliquots were withdrawn at different times i.e. 15, 30, 45, $60,90,120,180,240$ and $360 \mathrm{~min}$. The medium was replaced with equivalent volume of fresh medium to maintain constant volume and sink condition. Aliquots were analyzed using Hitachi U-2900 Spectrophotometer at wavelength 271.5 $\mathrm{nm}$.

\section{Data analysis}

The data were analyzed statistically by one-way ANOVA $(p<0.05)$ and, if significantly different, also by t-LSD. Drug release profiles were compared with a marketed extended-release product (MP) of THP using similarity factor $\left(f_{2}\right)$. Drug release data were computed with free open source software KinetDS $®$ [16] and DDSolver $®$ [17]. Several mathematic models were applied to determine and describe the drug releases from nanoclay-based matrix i.e. zero-order, first-order, Higuchi, Hixson-Crowell, quadratic and PeppasSahlin equation. The best fitting model based on coefficient of determination $\left(R^{2}\right)$ and AIC (Akaike's information criterion). Weibull model was used to determine the shape of curve release based on shape parameter curve $(\beta)$, the mechanism of drug release was determined by diffusion exponential value $(n)$ of KorsmeyerPeppas equation model.

\section{RESULTS}

Fig 1 showed the drug loading kinetics of THP/ZLT and THP/HTC. The ZLT showed higher drug loading after $1.5 \mathrm{~h}$, at initial time the HTC provided better drug loading than ZLT, all of the drug loading kinetic profiles showed that reducing of drug loading overtime after $3 \mathrm{~h}$ for HTC and $2 \mathrm{~h}$ for ZLT.

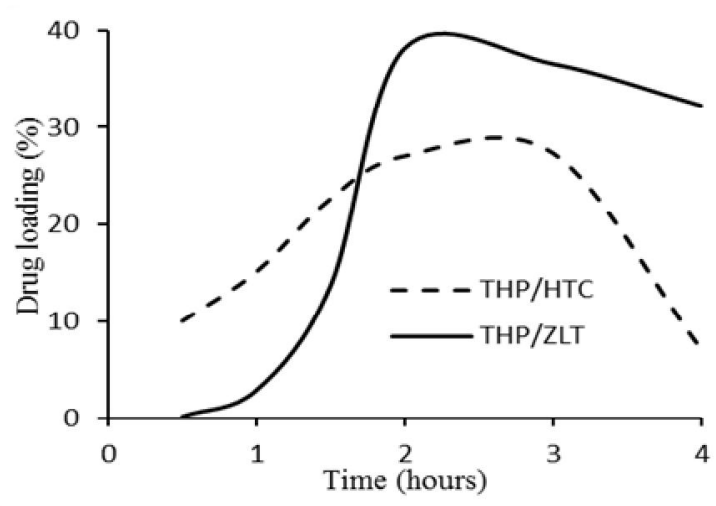

Figure 1: Drug loading kinetics of THP/Clays

The FTIR spectrum of THP and composites are presented in Fig. 2. The principal peaks of THP were at wavenumber $1716.65 \mathrm{~cm}^{-1}$ and 1666.50 $\mathrm{cm}^{-1}$ assigned carbonyl asymmetric and symmetric vibration respectively. The peaks at wavenumber $1566.20 \mathrm{~cm}^{-1}$ assigned $\mathrm{C}=\mathrm{N}$ vibration and $1188.15 \mathrm{~cm}^{-1}$ assigned $\mathrm{C}-\mathrm{N}$ vibration. The peaks at wavenumber around 1400 - $1500 \mathrm{~cm}^{-1}$ assigned ring stretching vibration and $3120.82 \mathrm{~cm}^{-1}$ assigned $\mathrm{N}-\mathrm{H}$ stretching vibration.

The physical properties of granules are presented in Table 2. The ZLT had higher tapped and bulk density than HTC. Increasing ZLT concentration gave no significant difference in bulk and tapped density $(p>0.05)$, while increasing HTC concentration reduced significantly the tapped, bulk density and compaction ability $(p<0.05)$. The moisture content of ZLT was higher than that of HTC ranging from $1.0-1.83 \%$ and $0.30-0.83 \%$, respectively. The flowability was shown by flow time and angle of repose which less than $7 \mathrm{sec}$ and $29^{\circ}$, respectively. 


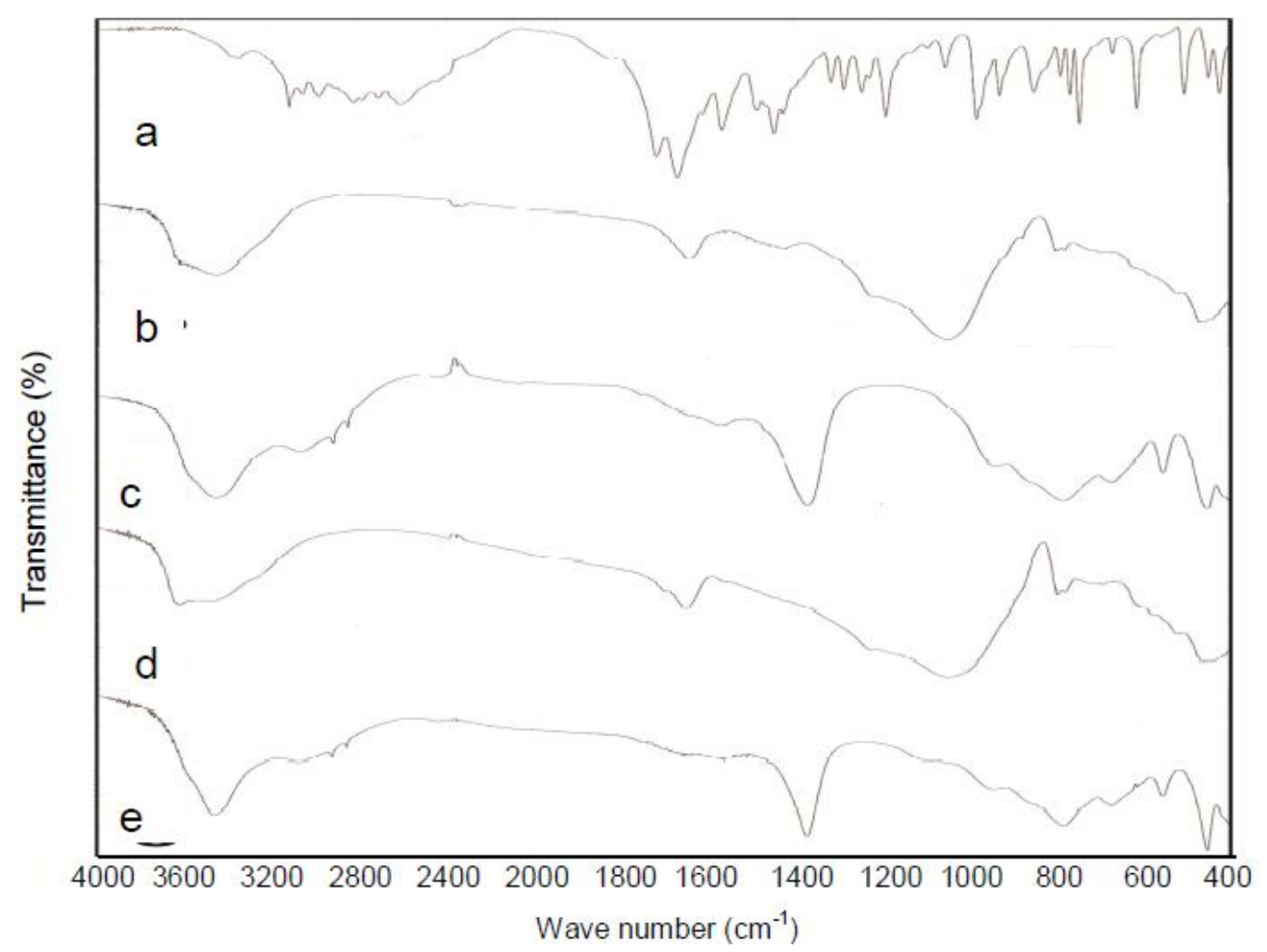

Figure 2: FTIR spectra of THP (a), ZLT (b), HTC (c), THP/ZLT (d), and THP/HTC composite (e)

Table 2: Physicochemical properties of formulation granules

\begin{tabular}{lllllll}
\hline Batch & $\begin{array}{l}\text { Bulk density } \\
(\mathbf{g} / \mathbf{m L})\end{array}$ & $\begin{array}{l}\text { Tapped } \\
\text { density } \\
(\mathbf{g} / \mathbf{m L})\end{array}$ & $\begin{array}{l}\text { Moisture } \\
\text { content }(\%)\end{array}$ & $\begin{array}{l}\text { Flow time } \\
(\mathbf{s} / \mathbf{1 0 0} \mathbf{g})\end{array}$ & $\begin{array}{l}\text { Compactibility } \\
(\mathbf{N})\end{array}$ & $\begin{array}{l}\text { Angle of } \\
\text { repose }\left({ }^{\circ}\right)\end{array}$ \\
\hline F1 & $0.546 \pm 0.007$ & $0.642 \pm 0.002$ & $0.30 \pm 0.00$ & $5.78 \pm 0.25$ & $94.7 \pm 3.2$ & $24.71 \pm 0.71$ \\
F2 & $0.612 \pm 0.012$ & $0.707 \pm 0.003$ & $1.00 \pm 0.00$ & $5.39 \pm 0.37$ & $97.9 \pm 9.5$ & $26.65 \pm 0.80$ \\
F3 & $0.600 \pm 0.009$ & $0.700 \pm 0.009$ & $1.30 \pm 0.00$ & $4.72 \pm 0.23$ & $120.5 \pm 7.7$ & $26.84 \pm 0.29$ \\
F4 & $0.612 \pm 0.004$ & $0.712 \pm 0.004$ & $1.83 \pm 0.29$ & $5.09 \pm 0.27$ & $124.7 \pm 11.9$ & $25.69 \pm 1.22$ \\
F5 & $0.571 \pm 0.000$ & $0.682 \pm 0.007$ & $0.30 \pm 0.00$ & $5.74 \pm 0.15$ & $78.3 \pm 7.0$ & $25.81 \pm 0.46$ \\
F6 & $0.488 \pm 0.000$ & $0.591 \pm 0.010$ & $0.30 \pm 0.00$ & $6.07 \pm 0.15$ & $43.8 \pm 0.63$ & $27.27 \pm 1.41$ \\
F7 & $0.471 \pm 0.006$ & $0.567 \pm 0.006$ & $0.83 \pm 0.29$ & $6.76 \pm 0.29$ & $35.3 \pm 2.9$ & $28.26 \pm 0.70$ \\
\hline
\end{tabular}

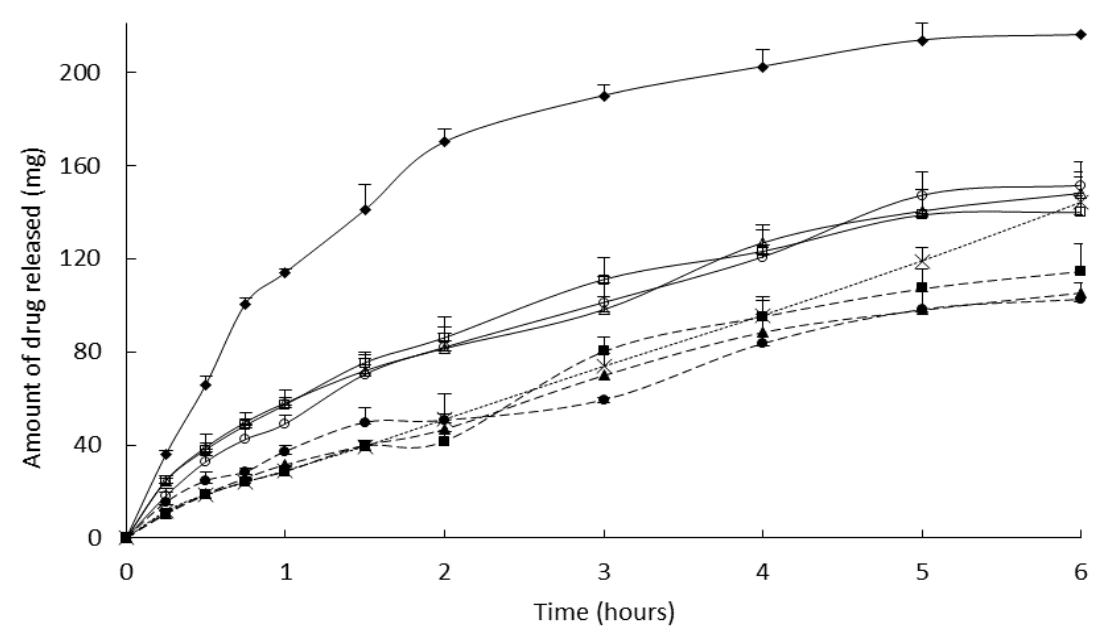

Figure 3: THP release profile from ZLT and HTC nanocomposites ( - - (F1), -०- (F2), - $-(F 3),-\square-(F 4),--\bullet--$ (F5), - - $\mathbf{\Delta - ~ - ~ ( F 6 ) , ~ - ~ - n - ~ - ~ ( F 7 ) ~ a n d ~ \cdots . . \cdots ~ ( M P ) ~}$ 
The drug release profiles of ZLT and HTC are presented in Fig. 3. The drug release of ZLT matrix was higher than that of HTC. The different matrix concentration provided similarity of release pattern. The formulation without matrix showed that the drug released completely after 4 $h$ and addition of ZLT and HTC extended the drug release up to $6 \mathrm{~h}$. The hardness and weight of tablet was not significant difference statistically $(p>0.05)$. Comparison of the drug release profiles using dissolution efficiency during $6 \mathrm{~h}$ (DE6h) and mean dissolution time (MDT) of ZLT and HTC under different concentrations provided no significant difference of DE6h and MDT ( $p>$ 0.05 ) and similarity factor was less than 50 .

The drug kinetics models are presented in Table 4. The best fitting of models was based on goodness of fit i.e. the highest $R^{2}$ and lowest AIC values. Zero-order release kinetics presented drug release rate $(k)$ and intercept $\left(F_{0}\right)$. Increasing $\mathrm{ZLT}$ concentration reduced $\mathrm{k}$ and increased $F_{0}$, on the other hand increasing HTC concentration increased $k$ and reduced $F_{0}$. The F3-F5 followed linear model and F2, F6 and F7 followed nonlinear model. Peppas-Sahlin model was the best fitting for all formulations followed by Weibull, Quadratic, Higuchi, first-order and zero-order release model. The different formulations showed different of drug release kinetics. Increasing ZLT concentration increased the exponential diffusion value of Peppas-Sahlin model and increasing of HTC reduced the exponential diffusion value of Peppas-Sahlin.

Table 3: Physical properties of THP tablet and the release rate

\begin{tabular}{llllll}
\hline Batch & Hardness $(\mathbf{N})$ & $\begin{array}{l}\text { Weight variation } \\
(\mathbf{m g})\end{array}$ & $\mathrm{DE}_{\mathbf{6 h}}(\mathbf{\%})$ & $\begin{array}{l}\text { MDT } \\
(\mathbf{m i n})\end{array}$ & $\mathbf{f}_{\mathbf{2}}$ \\
\hline F1 & $110.4 \pm 6.6$ & $510.1 \pm 5.95$ & 81.85 & 65.39 & 2.47 \\
F2 & $112.0 \pm 8.7$ & $511 \pm 13.73$ & 48.43 & 122.43 & 32.27 \\
F3 & $109.7 \pm 5.3$ & $510 \pm 12.14$ & 48.83 & 129.03 & 30.33 \\
F4 & $109.4 \pm 5.2$ & $510 \pm 14.87$ & 48.88 & 105.12 & 28.87 \\
F5 & $111.4 \pm 5.7$ & $506.5 \pm 5.3$ & 32.13 & 134.25 & 39.06 \\
F6 & $115.0 \pm 10.8$ & $504.3 \pm 3.1$ & 32.88 & 138.27 & 42.32 \\
F7 & $114.6 \pm 8.8$ & $508.1 \pm 5.2$ & 35.29 & 142.96 & 48.57 \\
\hline
\end{tabular}

Table 4: Drug release kinetics and mechanism of nanoclays-based matrix

\begin{tabular}{|c|c|c|c|c|c|c|c|}
\hline Model & $\begin{array}{l}\text { Kinetic } \\
\text { parameter }\end{array}$ & F2 & F3 & F4 & F5 & F6 & F7 \\
\hline \multirow{4}{*}{ Zero-order } & $\mathrm{R}^{2}$ & 0.968 & 0.968 & 0.933 & 0.972 & 0.978 & 0.971 \\
\hline & $\mathrm{k}(\mathrm{mg} / \mathrm{min})$ & 0.386 & 0.352 & 0.338 & 0.251 & 0.282 & 0.321 \\
\hline & $\mathrm{F}_{0}(\%)$ & 12.90 & 16.49 & 17.73 & 9.40 & 6.46 & 4.90 \\
\hline & $\mathrm{AIC}$ & 54.77 & 53.01 & 59.90 & 45.03 & 44.64 & 50.29 \\
\hline \multirow{2}{*}{ First-order } & $\mathrm{R}^{2}$ & 0.983 & 0.941 & 0.927 & 0.914 & 0.982 & 0.983 \\
\hline & AIC & 46.78 & 57.17 & 58.86 & 54.17 & 40.81 & 42.86 \\
\hline \multirow{2}{*}{ Higuchi } & $\mathrm{R}^{2}$ & 0.967 & 0.989 & 0.987 & 0.961 & 0.934 & 0.891 \\
\hline & $\mathrm{AIC}$ & 53.16 & 40.38 & 41.45 & 46.12 & 53.75 & 61.38 \\
\hline \multirow{2}{*}{ Hixson-Crowell } & $\mathrm{R}^{2}$ & 0.960 & .896 & 0.863 & 0.887 & 0.968 & 0.978 \\
\hline & AIC & 55.09 & 62.80 & 65.14 & 56.85 & 46.50 & 45.39 \\
\hline \multirow{2}{*}{ Quadratic } & $\mathrm{R}^{2}$ & 0.978 & 0.942 & 0.962 & 0.940 & 0.992 & 0.985 \\
\hline & AIC & 51.26 & 58.94 & 54.18 & 52.53 & 35.24 & 43.82 \\
\hline \multirow{5}{*}{ Peppas-Sahlin } & $\mathrm{R}^{2}$ & 0.995 & 0.995 & 0.998 & 0.983 & 0.993 & 0.980 \\
\hline & $\mathrm{k}_{1}$ & -9.059 & 2.777 & 1.678 & 2.010 & -2.316 & -2.003 \\
\hline & $\mathrm{k}_{2}$ & 7.401 & -0.007 & -0.010 & 0.082 & 2.048 & 1.526 \\
\hline & $\mathrm{M}$ & 0.232 & 0.573 & 0.726 & 0.469 & 0.297 & 0.330 \\
\hline & AIC & 37.80 & 37.46 & 26.81 & 41.93 & 35.20 & 48.43 \\
\hline \multirow{3}{*}{ Weibull } & $\mathrm{R}^{2}$ & 0.994 & 0.993 & 0.997 & 0.981 & 0.995 & 0.984 \\
\hline & B & 1.84 & 2.24 & 1.15 & 2.30 & 1.38 & 2.79 \\
\hline & AIC & 39.51 & 39.67 & 31.83 & 42.92 & 32.56 & 46.22 \\
\hline \multirow{3}{*}{$\begin{array}{l}\text { Korsmeyer- } \\
\text { Peppas }\end{array}$} & $\mathrm{R}^{2}$ & 0.994 & 0.994 & 0.988 & 0.982 & 0.993 & 0.979 \\
\hline & $\mathrm{N}$ & 0.622 & 0.549 & 0.518 & 0.606 & 0.704 & 0.777 \\
\hline & AIC & 38.50 & 35.58 & 42.79 & 40.48 & 34.01 & 46.77 \\
\hline
\end{tabular}

$k_{1}=$ constant of Fickian diffusion, $k_{1}=$ constant of non-Fickian diffusion, $m=$ exponential diffusion of PeppasSahlin equation 


\section{DISCUSSION}

Preliminary study revealed that nanocomposite between THP as drug model with slightly watersoluble drug and clays (ZLT and HTC) had ability to load the drug into the pores. The drug loading shows the abilities of the clays to load the drug as guest molecules into the pores. The drug loading using ZLT and HTC as clays and THP as drug studied for the time dependent is presented in Fig. 1. Among both of clays, the ZLT showed better drug loading than HTC. Overall, the drug loading of THP/ZLT and THP/HTC decreased with increasing of composite time, thus indicated the interaction between the clays and drug as reversible interaction.

The FTIR spectra of composite between THP and ZLT or HTC are shown in Fig. 2, there was the composite spectra followed the native of ZLT or HTC spectra, hence it was no significant change of the native clay spectra and disappearance of THP spectra, these indicated the interaction between drug and ZLT/HTC and the drug loaded into nanoporous of ZLT/HTC.

Based on the results of the physical properties of granules are presented in Table 2, the granules using ZLT and HTC as matrices had good fluidity and compaction ability. Improving concentration of ZLT, increased the compaction ability and fluidity, although improving concentration of HTC, decreased the fluidity and compaction ability. The desirable flow time for 100 grams of granule was less than $10 \mathrm{sec}$ and angle of repose less than $30^{\circ}$ [18]. The flowability was affected by some factors such as moisture, density, particle size distribution, porosity and cohesiveness between the particles. The test result of particle size distribution showed that particle size distributed normally and fines of granule were less than $10 \%$ (data not shown). Compaction ability was described from crushing force of tablet, the higher of compactibility value of granule mass, will make it easily compressible and produce compact mass with relatively low pressure. Weight of tablets ranged from 504.3 to $511 \mathrm{mg}$ with low standard deviation.

The drug release profiles from controlled release tablets are shown in Fig 3 . The drug release profile showed that HTC matrix released THP slower than the ZLT matrix. The drug loaded into the nanoporous of the nanoclays (ZLT and HTC), controlled drug release in these matrices are governed by size selectivity and pore size [12]. The different concentrations of ZLT and HTC matrix showed no significant difference on $\mathrm{DE}_{360}$ and MDT $(p>0.05)$. Increasing of the ZLT concentration showed no significant difference in
$\mathrm{DE}_{360}$ and decreasing of MDT $(p>0.05)$, moreover increasing the HTC concentration significantly increased MDT $(p<0.05)$. The drug release from tablet using HTC and ZLT as matrix was retarded and released up to $6 \mathrm{~h}$. It was indicated by decreasing $\mathrm{DE}_{6 \mathrm{~h}}$ and increasing MDT. $f_{2}$ value for all the formulations were less than 50 , thus the drug release profiles different from marketed product release profiles [19]. The ZLT as clay-based matrix, increasing the concentrations decreased the $f_{2}$ value. The ZLT as matrix showed the initial burst release effect was shown by intercept of zero order release $\left(F_{0}\right)$, increasing of ZLT concentration increased the drug release at initial time. The release rate of marketed product formulation no significant difference with THP/ZLT nanocom-posite formulation $(p>0.05)$, the different release profiles was affected by amount of drug release at initial time, the ZLT released higher amount of drug than HTC at initial time, but the marketed product formulation released the drug with constant rate (followed zero-order release).

The THP/HTC nanocomposite tablet formulation showed that increasing HTC concentrations increased the $f_{2}$ value and decreased the drug release at initial time. Different drug release profiles between marketed product formulation and THP/HTC nanocomposite formulation were affected by a decrease the release rate of HTC nanocomposite after $3 \mathrm{~h}$. The drug bounded in the interlayer of clays, thus the drug released slowly. The HTC has limitation in wettability, thus reduced and avoided the initial burst release effect. The release profile in initial time of HTC formulation showed similarity with marketed formulation, although after $2 \mathrm{~h}$ burst release effect was shown. The release rate after $4 \mathrm{~h}$ decreased constantly. ZLT and HTC as matrix showed initial burst release effect using freely water-soluble drug as drug model [20]. The exponential value between 0.45 to 0.89 indicate that THP release from nanoclays (HTC and ZLT) was governed by diffusion and erosion of the matrices.

Based on the drug releases kinetic and mechanism models are presented in Table 4, THP release kinetic of nanoclay matrices could be described by the Peppas-Sahlin model's with the highest coefficient of determination and lowest of AIC value. Peppas and Sahlin model describe the drug release in combination of Fickian diffusional contribute with non-Fickian one in a linear manner [21,22], thus the drug release from nanocomposite of the ZLT or HTC followed combination Fickian and non Fickian release mechanism. 


\section{CONCLUSION}

Both HTC and ZLT are potential drug carriers and capable to load the drug as guest molecule into the pores in reversible interaction and time dependent. The HTC provided drug release more retardant than ZLT as matrix, drug releases under different concentrations were to be found no statistically different from one another of both matrices. The kinetics of drug releases followed Peppas-Sahlin model and linear model. The mechanism of drug releases were anomalous transport which combines Fickian and nonFickian diffusional release.

\section{ACKNOWLEDGEMENT}

The authors would like to thank Sebelas Maret University with DIPA PNBP Superior Faculty of Mathematics and Science Grant 2014, Grant No.501/UN27.11/PN/2014 for financial support of this work.

\section{REFERENCES}

1. Colombo P, Sonvico F, Colombo G, Bettini R. Novel platforms for oral drug delivery. Pharm Res 2009; 26 : 601-613.

2. Kamarudin NHN, Jalil AA, Triwahyono S, Artika V, Salleh NFM, Karim AH, Jaafar NF, Sazegar MR, Mukti RR, Hameed $B H$, Johari $A$. Variation of the crystal growth of mesoporous silica nanoparticles and the evaluation to ibuprofen loading and release. J Colloid Interf Sci 2014; 421: 6-13.

3. Viseras C, Cerezo P, Sanches R, Salcedo I, Aguzzi C. Current challenges in clay minerals for drug delivery. Appl Clay Sci 2010; 48: 291-295

4. Augustine RL. Heterogeneous Catalysis for The Synthetic Chemist. New York: Marcel Dekker Inc; 1996.

5. Hua S, Yang $H$, Wang A. A pH-sensitive nanocomposite microsphere based on chitosan and montmorillonite with in vitro reduction of the brust release effect. Drug Dev and Ind Pharm 2010; 36(9): 1106-1114.

6. Zheng JP, Luan L, Wang HY, Xi LF, Yao KD. Study in ibuprofen/montmorillonite intercalation composite as drug release system. Appl Clay Sci 2007; 36: 297301.

7. Aguzzi C, Cerezo P, Viseras C, Caramella C. Use of clays as drug delivery system: possibilities and limitation. Appl Clay Sci 2007; 36: 22-36.

8. Suresh R, Borkar SN, Sawant VA, Shende VS, Dimble SK. Review article: nanoclay drug delivery system. Int J Pharm Sci and Nanotech 2010; 3(2): 901-905.
9. Gonzales G, Saqarzazu A, Zoltan T. Influence of microstructure in drug release behavior of silica nanocapsules, J Drug Deliv 2013; 1: 1-8.

10. Zhang Y, Xu C, He Y, Wang X, Xing F, Qiu H, Liu Y, Ma $D$, Lin T, Gao J. Zeolit/polimer composite hollow microspheres containing antibiotics and in vitro drug release. J Biomater Sci Polym 2011; 22: 4-6.

11. Krajisnik D, Dakovic A, Melenovic A, Djekic L, Kragovic $M$, Dobricic V, Milic J. An investigation of diclofenac sodium release from cetyl pyridinium xhloeise modified natural zeolite as a pharmaceutical excipient. Micropor Mesopor Mat 2013; 167: 94-101.

12. Cavani F, Trifiro F, Vaccari A. Hydrotalcite-type anionic clays: preparation, properties and application. Catal Today 1991; 11: 173-301.

13. San roman MS, Holgado MJ, Salinas B, Rives V. Drug release from double hydroxides and from their polylactic acid (PLA) nanocomposites. Appl Clay Sci 2013; 71: 1-7.

14. Perioli L, Posati T, Nocchetti M, Bellezza F, Contantino $U$, Cipiciani $A$. Intercalation and release of antiinflamatory drug diclofenac in nanosized ZnAl hydrotalcite-like compound. Appl Clay Sci 2011; 53: 347-378.

15. Perioli L, Ambrogi V, di Nauta L, Nocchetti M, Rossi C. Effects of hydrotalcite-like nanostructured compounds on biopharmaceutical properties and release of BCS class II drug: the case of flurbiprofen. Appl Clay Sci 2011; 51: 407-413.

16. Mendyk, Jachowicz R, Fijorek K, Dorozynski P, Kulinowski P, Polak S. KinetDS: an open source software for dissolution test daya analysis. Dissolut Technol 2012; 19 (1): 6-11.

17. Zhang Y, Huo M, Zhou J, Zou A, Li W, Yao C, Xie S. DDSolver: an add-in progam for modelling and comparison of drug dissolution profile. APPS J 2010; 12: 263-272.

18. Fudholi A. Methodology Formulation in Direct Compression. Medika 1983; 7(9): 586-593.

19. Shah VP, Tsong Y, Sathe P, Liu JP. In vitro dissolution profile comparison-statistics and analysis of the similarity factor (f2). Pharm Res 1998; 15: 889-896.

20. Ainurofiq A, Choiri S. Application of montmorillonite, zeolite, and hydrotalcite nanocomposite clay-drug as drug carrier of sustained release tablet dosage form. Indonesian J Pharm 2014; 25(3): 125-131.

21. Siepmann J, Peppas NA. Modelling of drug release from delivery system based on hydroxypropyl methylcellulose (HPMC). Adv Drug Del Rev 2012; 64: 163-174.

22. Peppas NA, Sahlin JJ. A simple equation for description of solute release III. Coupling of diffusion and relaxation. Int J Pharm 1989; 57: 169-172. 